\title{
N-Benzylbenzamides: a novel merged scaffold for orally available dual soluble epoxide hydrolase / peroxisome proliferator-activated receptor y modulators
}

\author{
René Blöcher ${ }^{1}$, Christina Lamers ${ }^{1}$, Sandra K. Wittmann ${ }^{1}$, Daniel Merk ${ }^{1}$, Markus Hartmann ${ }^{1}$, Lilia \\ Weizel', Olaf Diehl' ${ }^{1}$, Astrid Brüggerhoff ${ }^{1}$, Marcel Boß ${ }^{2}$, Astrid Kaiser ${ }^{1}$, Tim Schader ${ }^{1}$, Tamara Göbel', \\ Manuel Grundmann ${ }^{3}$, Carlo Angioni ${ }^{4}$, Jan Heering ${ }^{5}$, Gerd Geisslinger ${ }^{4}$, Mario Wurglics ${ }^{1}$, Evi Kostenis ${ }^{3}$, \\ Bernhard Brüne ${ }^{2}$, Dieter Steinhilber ${ }^{1}$, Manfred Schubert-Zsilavecz ${ }^{1}$, Astrid S. Kahnt ${ }^{1}$ and Ewgenij \\ Proschak ${ }^{1, *}$

\footnotetext{
${ }^{1}$ Institute of Pharmaceutical Chemistry, Goethe-University Frankfurt, Max-von-Laue-Strasse 9, D-60438 Frankfurt a. M., Germany. ${ }^{2}$ Institute of Biochemistry I, Goethe-University Frankfurt, Theodor-Stern-Kai 7, D-60590 Frankfurt a. M., Germany. ${ }^{3}$ Institute of Pharmaceutical Biology, Rheinische Friedrich-Wilhelms-Universität Bonn, Nussallee 6, D-53115 Bonn, Germany. ${ }^{4}$ Institute of Clinical Pharmacology, Goethe-University Frankfurt, Theodor-Stern-Kai 7, D-60590 Frankfurt a. M., Germany. 5 Project Group Translational Medicine and Pharmacology TMP, Fraunhofer Institute for Molecular Biology and Applied Ecology IME, Theodor-Stern-Kai 7, D-60590 Frankfurt a. M., Germany.
}

\section{Table of contents:}

Figures

Figure S1: Hydrolysis of 14b in Cos7 cell supernatant.

Figure S2: Oil Red staining of human differentiated primary adipocytes.

Figure S3: qPCR analysis of PPARy target genes in human primary adipocytes.

Figure S4: PK study of compound $\mathbf{1 b}$ after p.o. application in mice.

Figure S5: Brain drug concentration in mice after application of compound $\mathbf{1 b}$.

Figure S6: Metabolic stability of 1c and 14c in rat liver microsomes. Figure S7: Effect of compound 1c \& 14c on human GSK40 (FFA1) by Inositolphosphate 1 (IP1) measurement.

Figure S8: Effect of compound 1c \& 14c on murine GSK40 (FFA1) by Inositolphosphate 1 (IP1) measurement.

Figure S9: Differential scanning fluorimetry with PPARY LBD Methods

a. Plasmids used in the PPAR transactivation assay

b. Differentiation of human pre-adipocytes, mRNA isolation and analysis 
Blöcher et al., Supporting Information
c. In vivo PK studies
d. EET/DHET analysis
e. IP1 measurement
f. Hydrolysis measurement of $\mathbf{1 4 b}$ in the supernatant of Cos7 cells
g. Differential scanning fluorimetry (DSF) with PPARy LBD References 


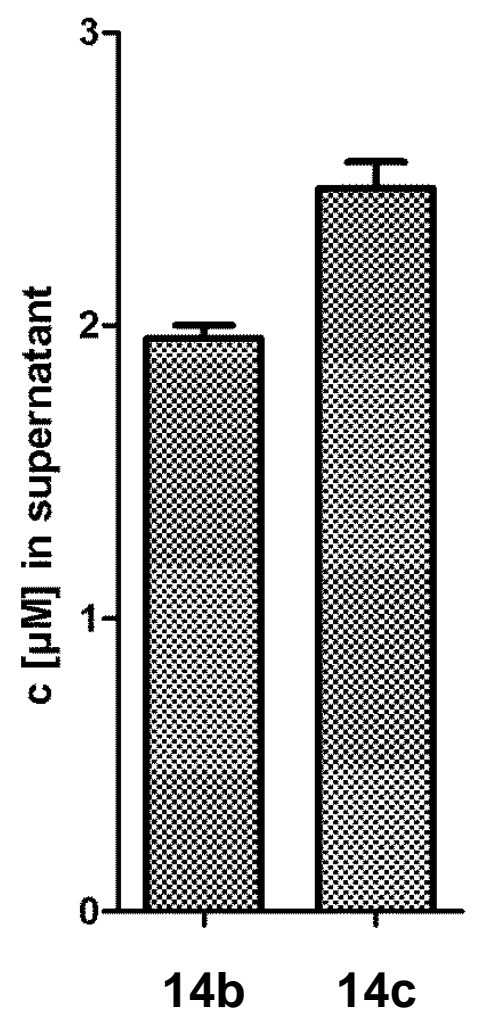

Figure $\mathbf{S 1}$ Conversion of ester $\mathbf{1 4 b}$ to acid $14 \mathrm{c}$ after $12 \mathrm{~h}$ incubation of cell culture medium containing $10 \mu \mathrm{M} 14 \mathrm{~b}$ with Cos 7 cells. Shown are mean values \pm s.e.m. each of six independent experiments. 

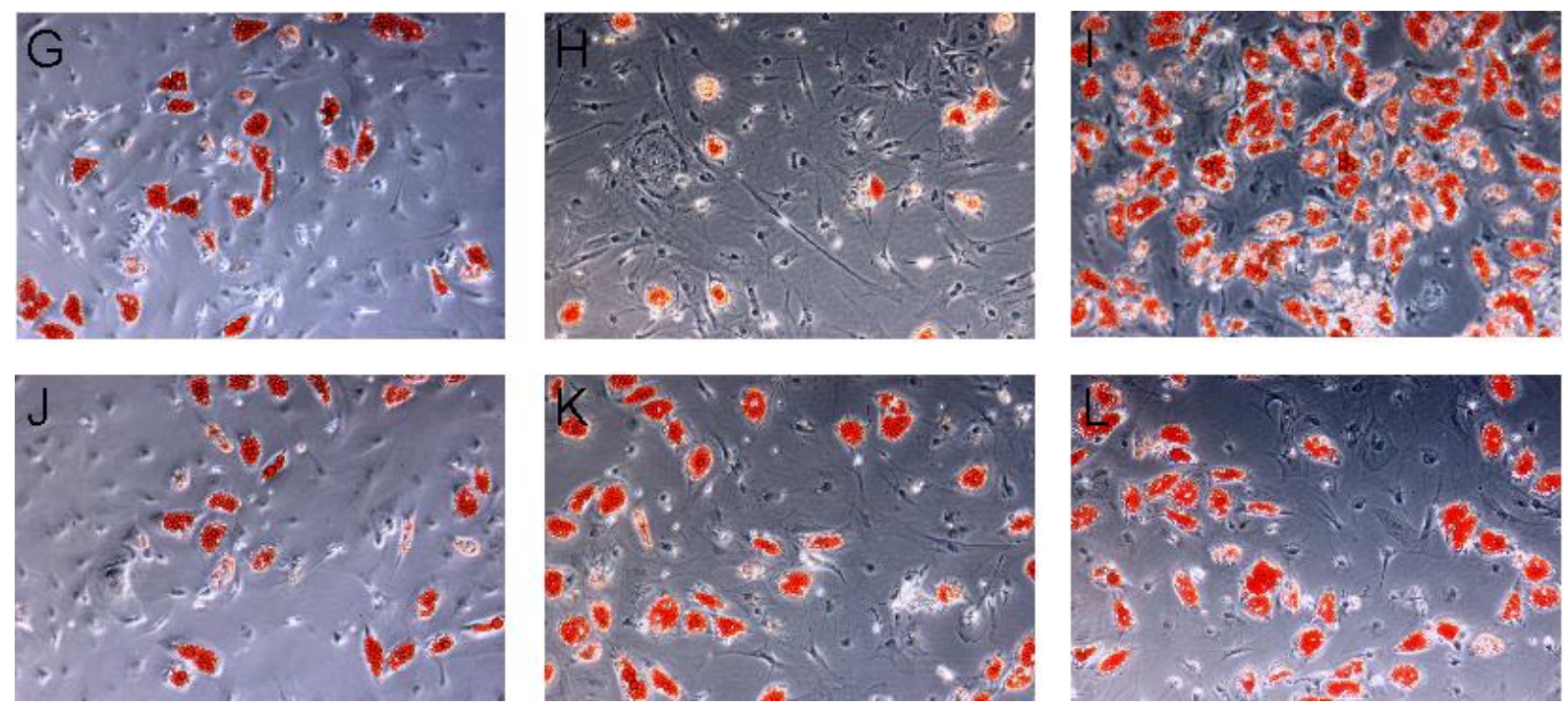

Figure S2 Oil Red O staining of human differentiated primary adipocytes. Pre-adipocytes were differentiated in the presence of various compounds. G: untreated control; $\mathrm{H}: 10 \mu \mathrm{M}$ CIU (sEH inhibitor); I: $2 \mu \mathrm{M}$ rosiglitazone (PPAR $\gamma$ agonist); J: $1 \mu \mathrm{M} 1 \mathrm{c} ; \mathrm{K}: 5 \mu \mathrm{M} 1 \mathrm{c}$; L: $10 \mu \mathrm{M}$ 1c. One representative experiment out of three is shown. The picture magnified 100-times. 

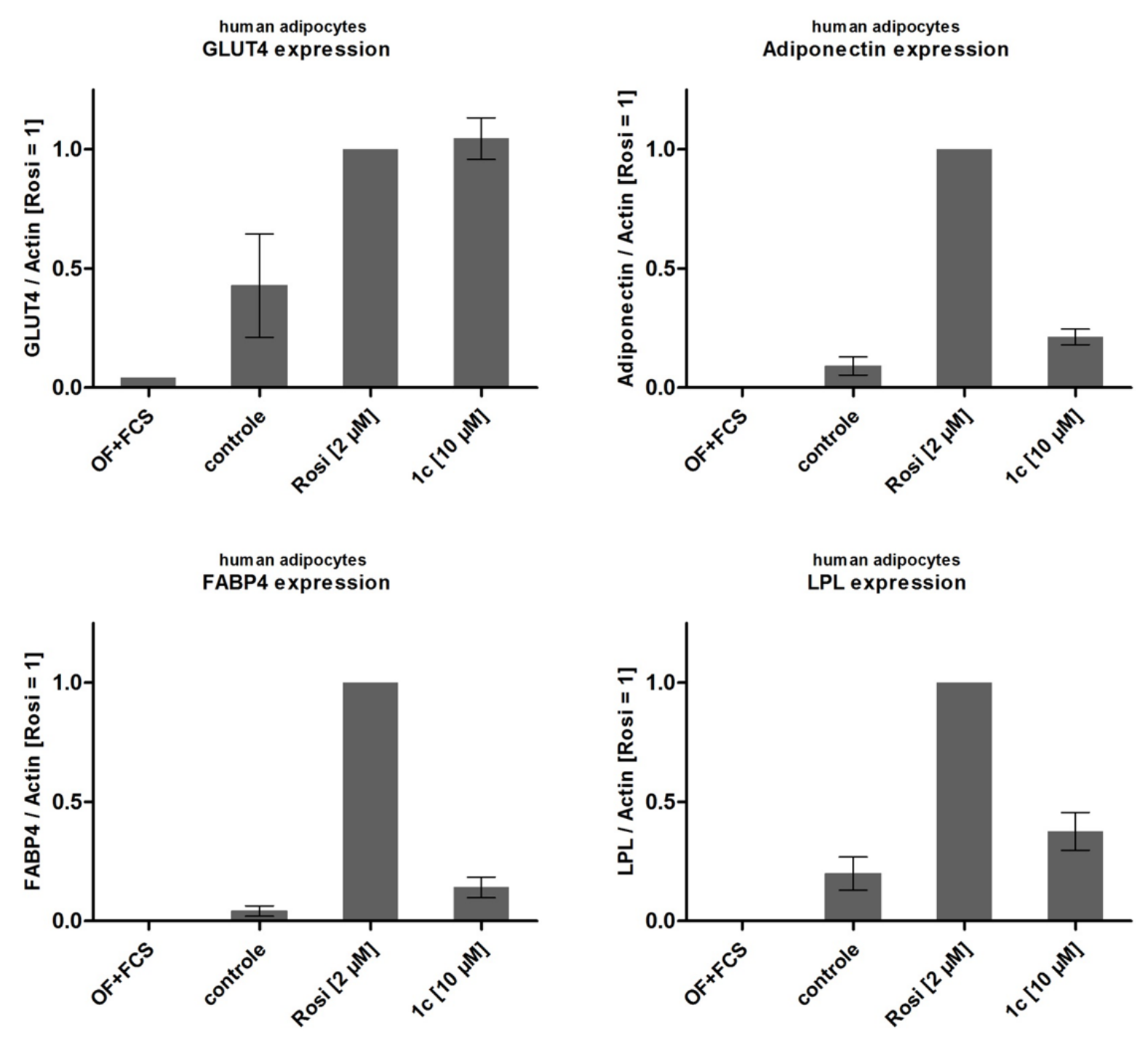

Figure S3. qPCR analysis of PPARy target genes (GLUT4, Adiponectin, FABP4, LPL) in human primary adipocytes differentiated in the presence of different stimuli. OF+FCS represents the differentiation of the cells only in basal medium. The control shows the experiment without PPARy stimuli. Shown are mean values \pm s.e.m. each of three independent experiments. 


\section{mouse kinetic study \\ $1 \mathrm{~b} 30 \mathrm{mg} / \mathrm{kg} \mathrm{bw}$}

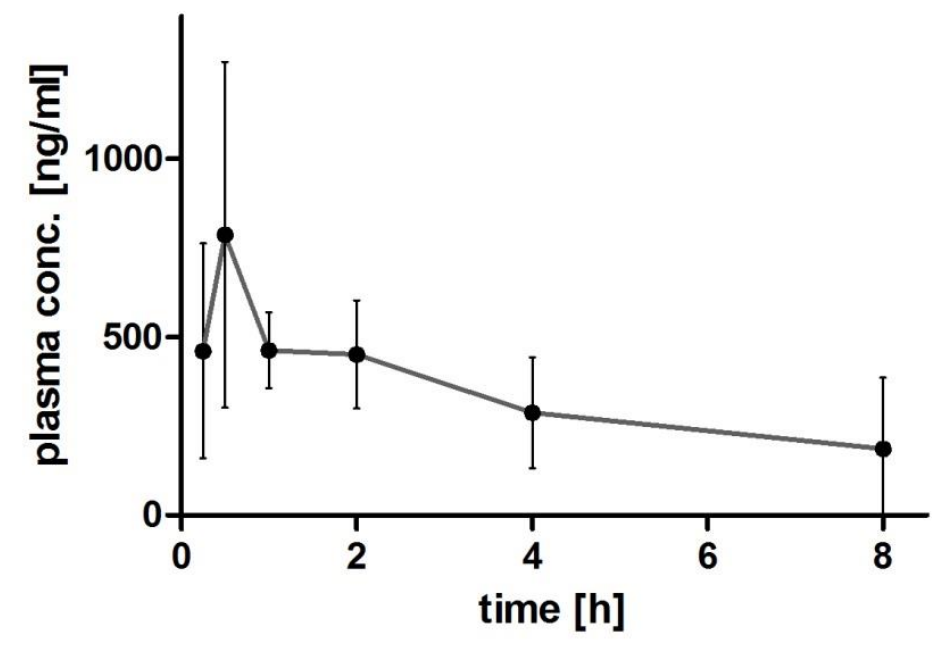

Figure S4. PK of $1 \mathbf{c}$ after p.o. application of $\mathbf{1 b}$ (single dose of $30 \mathrm{mg} / \mathrm{kg}$ ) in mice. Shown are mean values \pm s.e.m. from plasma of three mice per two timepoints.

mouse kinetic study

$30 \mathrm{mg} / \mathrm{kg}$ bw

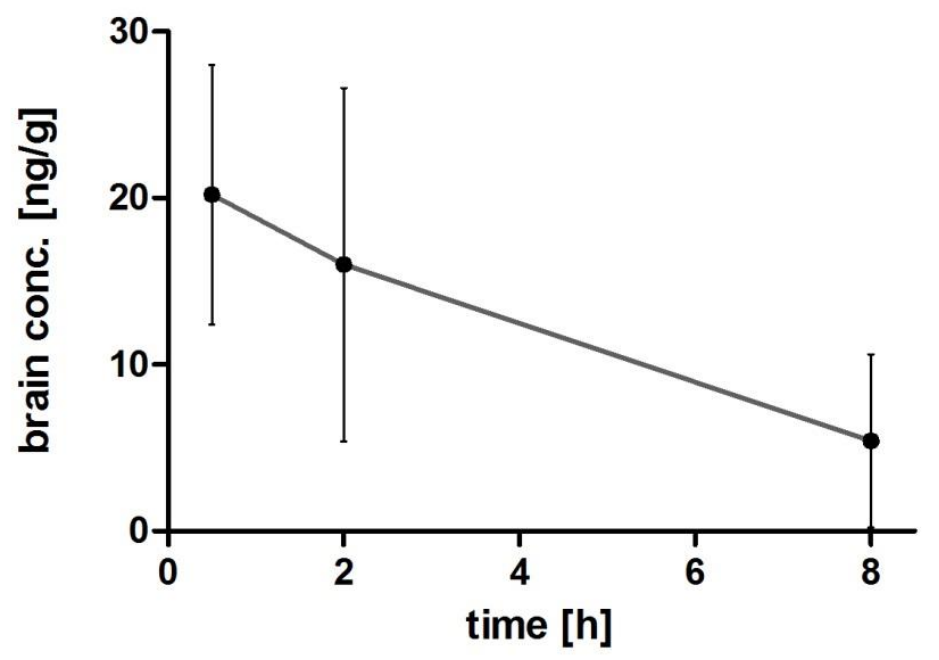

Figure S5. Brain concentration of 1c after p.o. application of $\mathbf{1 b}$ (single dose of 30 $\mathrm{mg} / \mathrm{kg}$ ) in mice. Shown are mean values \pm s.e. $\mathrm{m}$. from brain tissue of three mice per timepoint. 
a)

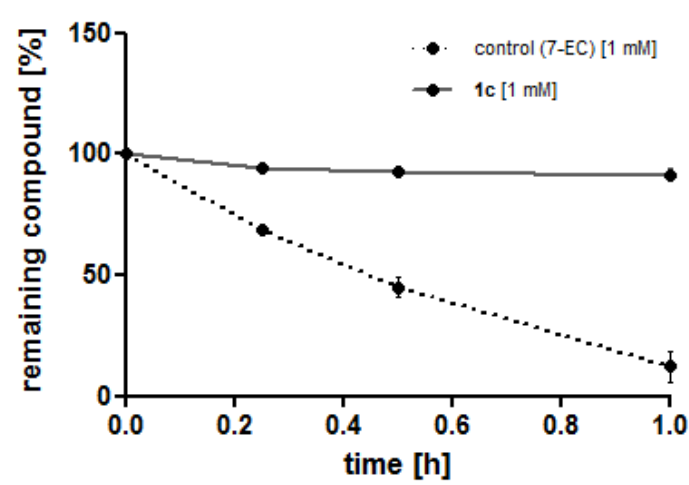

b)

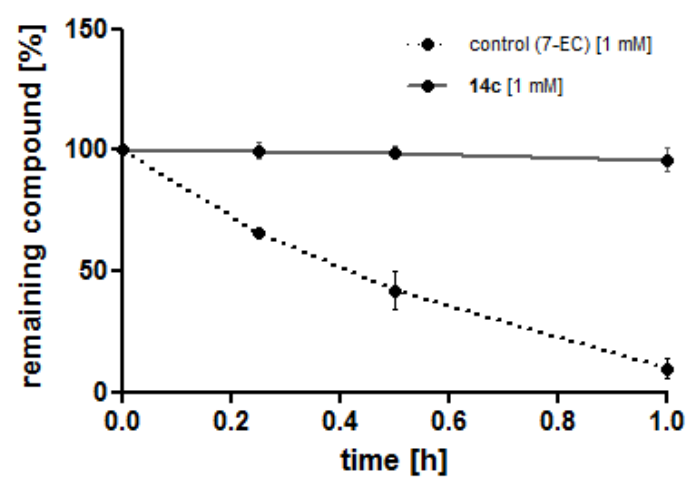

Figure S6. Metabolic stability of 1c (a) and 14c (b) in rat liver microsomes. Shown are mean values \pm s.e.m. of three independent experiments. 


\section{human FFA1-HEK}

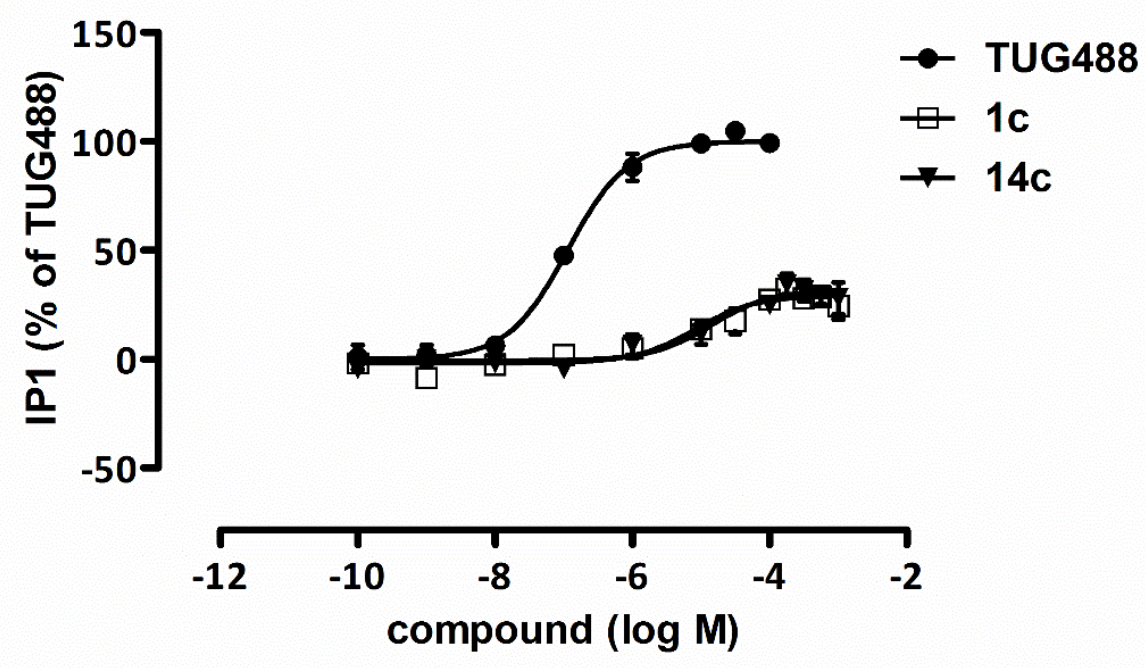

Figure S7. Effect of compound 1c \& 14c on GPR40 (FFA1) by Inositolphosphate 1 (IP1) measurement. Human recombinant HEK293 cells stably expressing hFFA1 were stimulated with the indicated compounds and IP1 accumulation was quantified. TUG488 was included as reference for robust FFA1 activation. ${ }^{1}{ }^{p E C_{50}}$ : 1c: $5.08 \pm$ $0.22 ; 14 c: 4.85 \pm 0.25$. Shown are mean values \pm s.e.m. of three independent experiments.

mouse FFA1-HEK

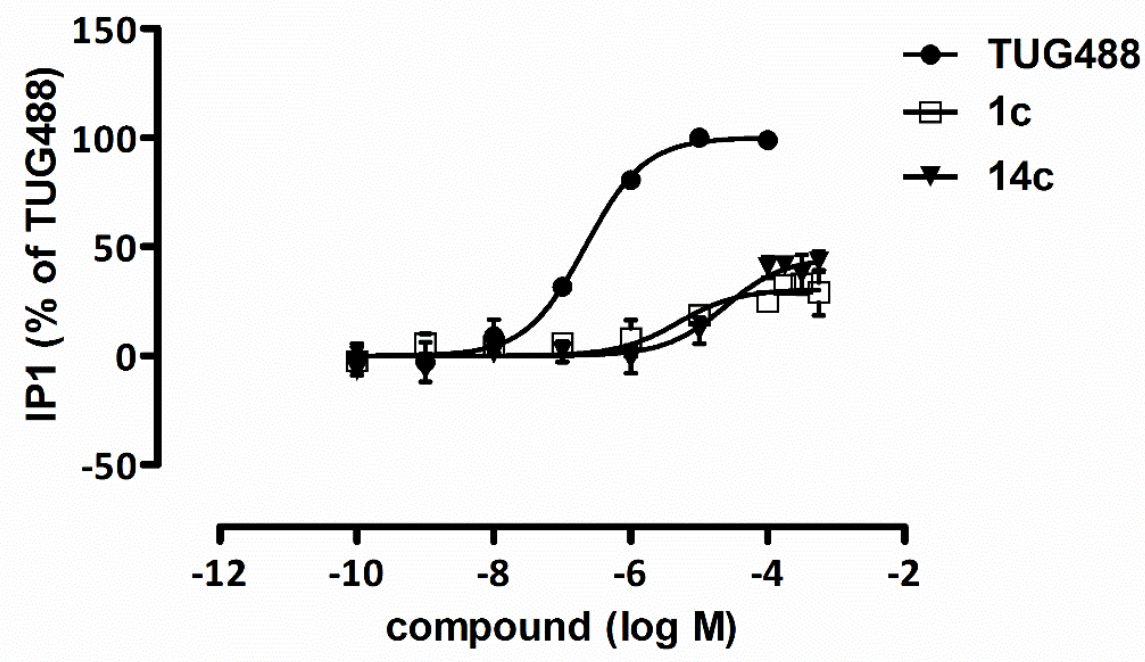

Figure S8. Effect of compound 1c \& 14c on GPR40 (mFFA1) by Inositolphosphate 1 (IP1) measurement. Human recombinant HEK293 cells stably expressing the mouse ortholog of FFA1 (mFFA1) were stimulated with the indicated compounds and IP1 accumulation was quantified. TUG488 ${ }^{1}$ was included as reference for robust mFFA1 activation. $\mathrm{pEC}_{50}$ : 1c: $5.31 \pm 0.31 ; \mathbf{1 4 c}: 4.63 \pm 0.23$. Shown are mean values \pm s.e.m. of three independent experiments. 

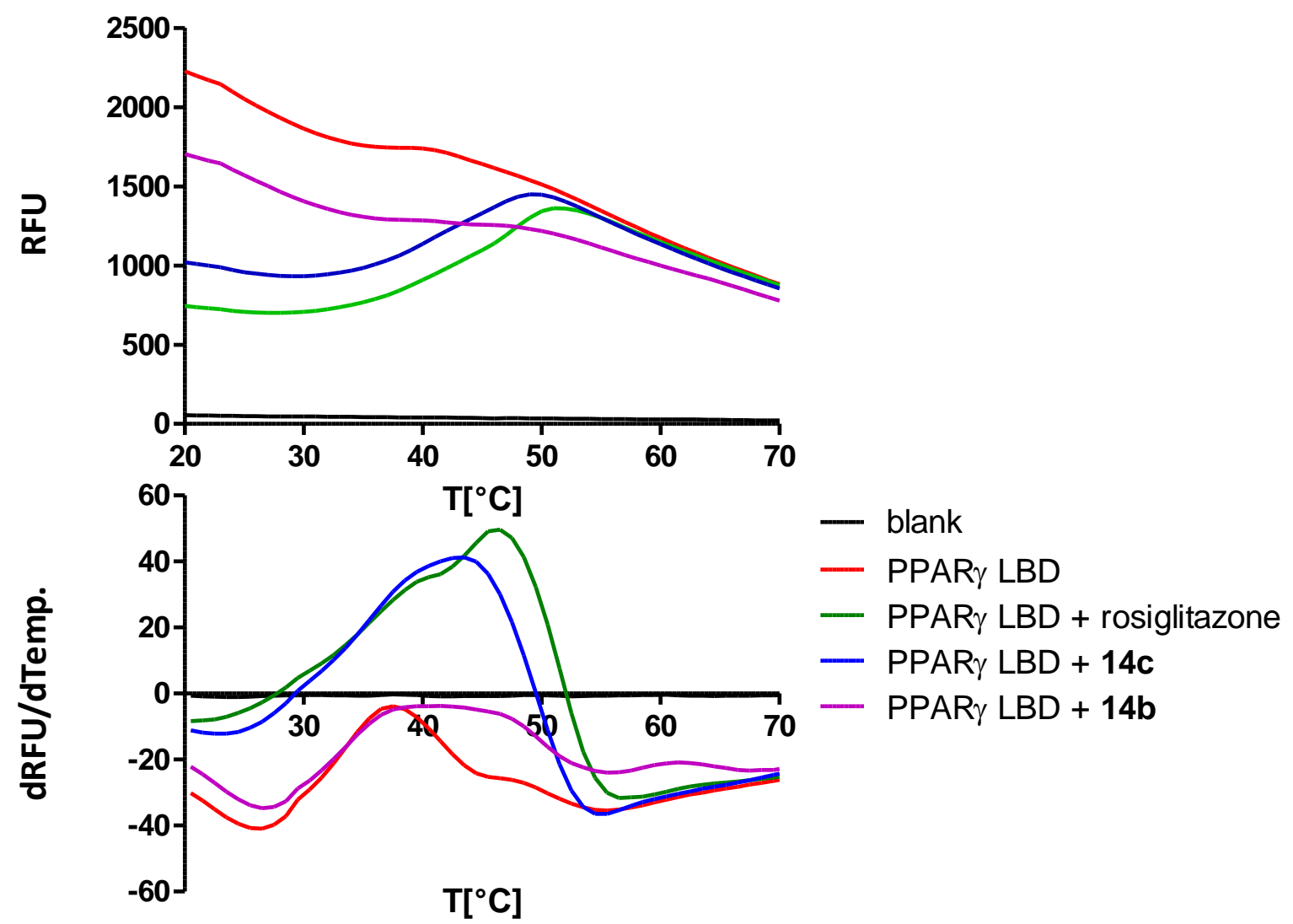

Figure S9. Differential scanning fluorimetry (DSF) of PPARY LBD in presence of ligands. Shown is a representative two independent experiments. 


\section{Methods}

\section{a. Plasmids used in the PPAR transactivation assay}

The Gal4-fusion receptor plasmids pFA-CMV-PPARa-LBD, pFA-CMV-PPARס-LBD and $\mathrm{pFA}-\mathrm{CMV}$-PPARY-LBD containing the hinge region and ligand binding domain (LBD) for each of the PPAR subtypes, respectively, were constructed by integrating cDNA fragments obtained from PCR amplification of human monocytes into the Smal/Xbal cleavage site of the pFA-CMV vector (Stratagene, La Jolla, CA, USA) and have already been published. The cDNA fragments consist of bps $499-1407$ (NM_005 036), bps 412 - 1323 (NM_006 238) and bps 610 - 1518 (NM_015 869) for PPARa, PPARס and PPARY, respectively. Frame and sequence of the fusion receptors were verified by sequencing. pFR-Luc (Stratagene) was used as reporter plasmid and pRL-SV40 (Promega) for normalization of transfection efficacy and cell growth.

\section{b. Differentiation of human preadipocytes, RNA isolation and analysis}

\section{Preparation of primary human preadipocytes and differentiation}

Human primary preadipocytes were obtained from stromal vascular fraction of subcutaneous fat from anonymous donors undergoing elective cosmetic surgery. Adipose tissue was digested by collagenase solution (0.3 U/ml in $1 \%$ BSA/PBS) for $45 \mathrm{~min}$ at $37{ }^{\circ} \mathrm{C}$ with constant shaking. Floating mature adipocytes were removed and the pellet containing the stromal vascular fraction was resuspended in erythrocyte lysis buffer. After consecutive filtration through $100 \mu \mathrm{m}, 70 \mu \mathrm{m}$ and $40 \mu \mathrm{m}$ cell strainers preadipocytes were seeded in DMEM/Ham's F12 (1:1) nutrient mixture supplemented with $10 \% \mathrm{FCS}, 33 \mu \mathrm{M}$ biotin and $17 \mu \mathrm{M}$ pantothenate. The following day, culture media was changed to QuickDiff medium (DMEM/Ham's F12 supplemented with $33 \mu \mathrm{M}$ biotin, $17 \mu \mathrm{M}$ pantothenate, $0.01 \mathrm{mg} / \mathrm{ml}$ transferrin, $20 \mathrm{nM}$ insulin, $100 \mathrm{nM}$ cortisol, $200 \mathrm{pM}$ T3, $25 \mathrm{nM}$ dexamethasone, $250 \mu \mathrm{M}$ IBMX and $2 \mu \mathrm{M}$ rosiglitazone). After 4 days the medium was changed to 3FC medium (QuickDiff medium without dexamethasone, IBMX and rosiglitazone). Adipocytes were cultured for additional 14 days before medium was changed to basal medium consisting of DMEM/Ham's F12 with biotin and panthotenate. This investigation conforms to the ethical principles outlined in the Declaration of Helsinki and was approved by the university ethics committee (Ethik-Kommission des Fachbereichs Medizin der Goethe-Universität Frankfurt am Main).

RNA isolation and analysis 
Total RNA was isolated using PeqGold RNAPure (Peqlab) according to manufacturer's instructions and was transcribed to cDNA using Maxima First Strand cDNA synthesis kit (Thermo Scientific), following manufacturer's instructions. Quantitative PCR was performed with iQ SYBR green Supermix (Bio-Rad) using a CFX96 (Bio-Rad) system. Expression was normalized to actin RNA.

\section{c. In vivo PK studies}

\section{po PK mouse study}

9 male RjOrl:Swiss (CD-1) mice (28-42 g body weight, purchased from Janvier Labs, France) were used in the present study. The animals were housed in a temperaturecontrolled room $\left(20-24^{\circ} \mathrm{C}\right)$ and maintained in a $12 \mathrm{~h}$ light/12h dark cycle. Food and water were available ad libitum. $30 \mathrm{mg} / \mathrm{kg}$ bw of compound $1 \mathrm{~b} \& 1 \mathrm{c}$ were applicate via gavage with $0.5 \%$ methylcellulose at an injection volume of $10 \mathrm{ml} / \mathrm{kg}$ in two different studies. Blood was sampled $15 \mathrm{~min}, 30 \mathrm{~min}, 1 \mathrm{~h}, 2 \mathrm{~h}, 4 \mathrm{~h}$ and $8 \mathrm{~h}$ after test item application and only $8 \mathrm{~h}$ after vehicle application. Each drug treated mouse was sampled twice $(0.25$ and $0.5 \mathrm{~h}, 1$ and $2 \mathrm{~h}, 4$ and $8 \mathrm{~h}$ ) via retro orbital puncture. Blood was collected in tubes containing lithium-heparin, stored on ice and subsequently centrifuged at $6000 \mathrm{rpm}$ for 10 minutes at $4^{\circ} \mathrm{C}$ (Heraeus biofuge fresco). The plasma was prepared within $45 \mathrm{~min}$ after sampling and kept at $-20^{\circ} \mathrm{C}$ until being assayed. For further kinetic and dynamic analysis the tissues (brain, liver, abdominal fat) were collected $30 \mathrm{~min}, 2 \mathrm{~h}$ and $8 \mathrm{~h}$ post dose, after the second plasma sampling of each drug treated mouse. Tissue of the vehicle group was sampled only once, $8 \mathrm{~h}$ post dose. A volume of $40 \mu \mathrm{l}$ acetonitrile containing the internal standard $(300 \mathrm{ng} / \mathrm{ml}$ Diazepam) was added to $20 \mu \mathrm{l}$ of mouse plasma sample, plasma calibration standard and plasma QC samples. Samples were vigorously shaken and centrifuged for 10 minutes at $6000 \mathrm{~g}$ and $20^{\circ} \mathrm{C}$. The particle free supernatant was diluted $1: 1$ with water. An aliquot was transferred to $200 \mu \mathrm{l}$ sampler vials and subsequently subjected to LC MS with an injection volume of $20 \mu \mathrm{l}$. The brain samples were homogenized in PBS $(1+1, w / v)$ using the Precellys 24/Dual homogenizer. A volume of $20 \mu \mathrm{l}$ of the brain homogenate was mixed $(1+1 \mathrm{v} / \mathrm{v} /)$ with $20 \mu \mathrm{l}$ mouse blank plasma. Then $80 \mu \mathrm{l}$ acetonitrile containing the internal standard $(300 \mathrm{ng} / \mathrm{ml}$ Diazepam) were added. Samples were vigorously shaken and centrifuged for 10 minutes at $6000 \mathrm{~g}$ and 20 ${ }^{\circ} \mathrm{C}$. The particle free supernatant was diluted 1:1 with water. An aliquot was transferred to $200 \mu \mathrm{l}$ sampler vials and subsequently subjected to LC MS with an injection volume of $20 \mu \mathrm{l}$. Mass spectrometry was performed on a TSQ Quantum Discovery Max triple quadrupole mass spectrometer equipped with an electrospray (ESI) interface (Thermo Fisher Scientific, USA) connected to a PC running the standard software Xcalibur 2.0.7. The HPLC pump flow rate was set to $600 \mu \mathrm{l} / \mathrm{min}$ and the test item was separated on a Kinetex Phenyl-Hexyl, $2.6 \mu \mathrm{m}, 50 \times 2.1 \mathrm{~mm}$ (Phenomenex, Germany) analytical column with a pre-column. Gradient elution with water $/ 0.1 \%$ formic acid as aqueous phase $(\mathrm{A})$ and acetonitrile $/ 0.1 \%$ formic acid as organic phase (B) was used: \% B (t (min)), 5(0-0.1)-97(0.8-1.7)-5(1.8-2.5). 


\section{2 week drinking water PK mouse study}

9 male C57BL/6JRj mice (23-27 g body weight, purchased from Janvier Labs, France) were used in the present study. The animals were housed in a temperaturecontrolled room $\left(20-24^{\circ} \mathrm{C}\right)$ and maintained in a $12 \mathrm{~h}$ light/12h dark cycle. Food and water were available ad libitum. 14c was not soluble in plain drinking water. For this reason, different cosolvents were used for different time periods of the study. A 3 $\mathrm{mg} / \mathrm{ml}$ stock solution of $14 \mathrm{c}$ was prepared by dissolution of $283.4 \mathrm{mg} 14 \mathrm{c}$ in $94.46 \mathrm{ml}$ ethanol. A volume of $10 \mathrm{ml}$ of this stock solution was added to $190 \mathrm{ml}$ tap water in a drinking bottle to obtain a final concentration of $0.15 \mathrm{mg} / \mathrm{ml}$ (estimated target dose of $30 \mathrm{mg} / \mathrm{kg}$ ). This was provided to the mice from the afternoon of day 1 until the afternoon of day 5 . No precipitates were observed in this mixture when it was removed from the cage on day 5. A $1.5 \mathrm{mg} / \mathrm{ml}$ stock solution of $14 \mathrm{c}$ was prepared mixing $100 \mathrm{mg} \mathrm{14c}$ in $66.7 \mathrm{ml} 1 \%$ Tween 80 . As the test item was not completely dissolved, the mixture was subjected to sonication at $37^{\circ} \mathrm{C}$. By mistake, a volume of $10 \mathrm{ml}$ of the resulting slightly opaque suspension was added to $190 \mathrm{ml}$ instead of 90 $\mathrm{ml}$ tap water in a drinking bottle and provided to the mice from the afternoon of day 5 until the afternoon of day 7 . This corresponds to a final concentration of only 0.075 $\mathrm{mg} / \mathrm{ml}$ (estimated dose of $15 \mathrm{mg} / \mathrm{kg} 14 \mathrm{c}$ in $0.05 \%$ Tween 80 ) A few precipitates were observed in this mixture when it was removed from the cage on day 7 . The $1.5 \mathrm{mg} / \mathrm{ml}$ stock solution of $14 \mathrm{c}$ of 20.9 .2014 was again subjected to sonication at $37^{\circ} \mathrm{C}$ and a volume of $10 \mathrm{ml}$ of the resulting slightly opaque suspension was added to $90 \mathrm{ml}$ tap water in a drinking bottle and provided to the mice from the afternoon of day 7 until the afternoon of day 10 . This corresponds to a final concentration of $0.15 \mathrm{mg} / \mathrm{ml}$ (estimated dose of $30 \mathrm{mg} / \mathrm{kg} 14 \mathrm{c}$ in $0.1 \%$ Tween 80 ). A few precipitates were observed in this mixture when it was removed from the cage on day 10 . A fresh 1.5 $\mathrm{mg} / \mathrm{ml}$ stock solution of $\mathbf{1 4 c}$ was prepared mixing $29.77 \mathrm{mg} 14 \mathrm{c}$ in $19.85 \mathrm{ml} 1 \%$ Tween 80 . The mixture was subjected to sonication at $37^{\circ} \mathrm{C}$. A volume of $10 \mathrm{ml}$ of the resulting slightly opaque suspension was added to $90 \mathrm{ml}$ tap water in a drinking bottle and provided to the mice from the afternoon of day 10 until the afternoon of day 14. This corresponds to a final concentration of $0.15 \mathrm{mg} / \mathrm{ml}$ (estimated dose of 30 $\mathrm{mg} / \mathrm{kg} 14 \mathrm{c}$ in $0.1 \%$ Tween 80 ). A few precipitates were observed in this mixture when it was removed from the cage on day 14. The test item was dissolved in drinking water freshly every 2-4 days and provided to the animals for a total duration of 14 days. Water intake was recorded per cage, every time before provision of the fresh solution. Water intake was recorded per cage, every time before provision of the fresh solution. The corresponding final concentration was $0.15 \mathrm{mg} / \mathrm{ml}$ (estimated dose of $30 \mathrm{mg} / \mathrm{kg} 14 \mathrm{c}$ in $0.1 \%$ Tween 80 ). Blood was sampled on day 7 and 10 , collected from the retrobulbar venous plexus of each mouse under short isoflurane anesthesia, in tubes containing lithium-heparin. Blood was stored on ice and subsequently centrifuged at $6000 \mathrm{rpm}$ for 10 minutes at $4^{\circ} \mathrm{C}$ (Heraeus biofuge fresco). The plasma was prepared within $45 \mathrm{~min}$ after sampling and was kept at $20^{\circ} \mathrm{C}$ until being assayed. After 14 days plasma and tissue (complete liver, both 
kidneys, pancreas, abdominal fat) was sampled for further dynamic studies. The whole plasma was collected as described bevor. For tissue collection, mice were sacrificed by cervical dislocation. Tissues were immediately frozen in liquid nitrogen and stored at $-80^{\circ} \mathrm{C}$ until analyzed. Concentration of the test item was only determined in plasma due the same method described under section PO PK mouse study.

\section{d. EET/DHET ratio analysis}

Determination of Epoxyeicosatrienoicacids (EETs) and their metabolites Dihydroxyepoxyeicosatrienoicacids (DHETS) by LC-MS/MS

5.6 EET, 8.9 EET, 11.12 EET, 14.15 EET and their further dehydro metabolites content of the extracted samples were analyzed employing liquid chromatography tandem mass spectroscopy (LC-MS/MS). The LC-MS/MS system comprised an API 5500 QTrap (AB Sciex, Darmstadt, Germany), equipped with a Turbo-V-source operating in negative ESI mode, an Agilent 1200 binary HPLC pump and degasser (Agilent, Waldbronn, Germany) and an HTC Pal autosampler (Chromtech, Idstein, Germany) fitted with a $25 \mu \mathrm{L}$ LEAP syringe (Axel Semrau GmbH, Sprockhövel, Germany). High purity nitrogen for the mass spectrometer was produced by a NGM 22-LC/MS nitrogen generator (cmc Instruments, Eschborn, Germany). All substances were obtained from Cayman Chemical, Ann Arbor, MI, USA. Stock solutions with $2500 \mathrm{ng} / \mathrm{ml}$ of all analyte were prepared in methanol. Working standards were obtained by further dilution with a concentration range of $0.1-250 \mathrm{ng} / \mathrm{ml}$ for epoxyeicosatrienoicacid and their dehydrometabolites respectively. Sample extraction was performed with liquid-liquid-extraction. Therefore $150 \mu \mathrm{l}$ of matrix homogenates were gently mixed with $20 \mu \mathrm{l}$ of internal standard (5.6 EET-d11, 8.9 EET-d8, 11.12 EET-d8 and 14.15 EET-d8 all with a concentration of $200 \mathrm{ng} / \mathrm{ml}$ in methanol), and were extracted twice with $600 \mu \mathrm{L}$ of ethyl acetate. Samples for standard curve and quality control were prepared similarly, instead of $150 \mu \mathrm{l}$ of matrix homogenates, $150 \mu \mathrm{L}$ PBS were added further $20 \mu \mathrm{L}$ methanol $20 \mu \mathrm{L}$ working standard and $20 \mu \mathrm{L}$ internal standard were added. The organic phase was removed at a temperature of $45^{\circ} \mathrm{C}$ under a gentle stream of nitrogen. The residues were reconstituted with $50 \mu \mathrm{L}$ of methanol/water/ $(50: 50, \mathrm{v} / \mathrm{v})$, centrifuged for 2 minutes at $10,000 \mathrm{~g}$ and then transferred to glass vials (Macherey-Nagel, Düren, Germany) prior to injected into the LC-MS/MS system. For the chromatographic separation a Gemini NX C18 column and precolumn were used $(150 \mathrm{~mm} \times 2 \mathrm{~mm}$ i. d., $5 \mu \mathrm{m}$ particle size and $110 \AA$ pore size from Phenomenex, Aschaffenburg, Germany). A linear gradient was employed at a flow rate of $0.5 \mathrm{ml} / \mathrm{min}$ mobile phase with a total run time of 17.5 minutes. Mobile phase was A water/ammonia (100:0.05, $\mathrm{v} / \mathrm{v})$ and $\mathrm{B}$ acetonitrile/ammonia $(100: 0.05, \mathrm{v} / \mathrm{v})$. The gradient started from $85 \% \mathrm{~A}$ to $10 \%$ within 12 min this was held for $1 \mathrm{~min}$ at $10 \%$ A. Within $0.5 \mathrm{~min}$ the mobile phase shifted back to $85 \% \mathrm{~A}$ and was held for $3.5 \mathrm{~min}$ to equilibrate the column for the next sample. The injection volume of samples was $20 \mu \mathrm{L}$. Quantification was performed with Analyst Software V 1.5.1 (Applied Biosystems, Darmstadt, Germany) employing 
the internal standard method (isotope- dilution mass spectrometry). Ratios of analyte peak area and internal standard area ( $\mathrm{y}$-axis) were plotted against concentration ( $\mathrm{x}$ axis) and calibration curves were calculated by least square regression with $1 /$ concentration2 weighting.

\section{e. Method of IP1 (inositolmonophosphate) measurement}

\section{Cell culture}

Stably transfected Flp-In ${ }^{T M}$ T-REx ${ }^{T M} 293$ cells (Invitrogen) were cultured in Dulbecco's modified Eagles's medium (DMEM) containing 10\% (v/v) fetal bovine serum (FBS), penicillin $(100 \mathrm{U} / \mathrm{mL})$, streptomycin $(100 \mu \mathrm{g} / \mathrm{mL})$, Hygromycin B $(100$ $\mu \mathrm{g} / \mathrm{mL}$ ) and Blasticidin $(15 \mu \mathrm{g} / \mathrm{mL})$ at $37^{\circ} \mathrm{C}$ and $5 \% \mathrm{CO}_{2}$. All experiments were carried out after inducing receptor expression with $1 \mu \mathrm{g} / \mathrm{mL}$ doxycycline for approximately 18 hours, according to manufacturer's instructions (Invitrogen).

\section{IP1 measurement}

Compound activity on the Gq coupled FFA1 receptor constructs was assessed by measuring intracellular level of inositolmonophosphate (IP1) using the $\mathrm{HTRF}^{\circledR}$-IP-One kit (Cisbio International) according to manufacturer's instructions. Briefly, 10,000 receptor expressing cells were seeded into a 384 well microplate and incubated 20 minutes at $37^{\circ} \mathrm{C}$. The cells were then stimulated with agonist for 30 minutes and IP levels were quantified using the $\mathrm{HTRF}^{\circledR}$-IP-One kit and the Mithras LB 940 multimode reader (Berthold Technologies) using emission/excitation filter of $665 \mathrm{~nm} / 620 \mathrm{~nm}$. Data analysis and nonlinear regression curve fitting were carried out using the GraphPad Prism ${ }^{\circledR}$ software v5.04 (Graphpad Software).

\section{f. Hydrolysis measurement of $14 b$ in the supernatant of Cos7 cells}

Cos 7 cells were seeded in 6-well plates $\left(10^{6}\right.$ cells per well). $24 \mathrm{~h}$ later, cells were incubated with 14b (10 $\mu \mathrm{M}$ in OptiMEM containing $1 \% \mathrm{PS})$ for $12 \mathrm{~h}$. Then, supernatant was collected and diluted with one volume cold $\mathrm{MeOH}$, filtered $(0.45$ $\mu \mathrm{m})$ and then used for HPLC analysis. HPLC analysis was performed on a Varian ProStar with a MultoHigh 100 (RP18, 250*4 mm) column with pre-column. Parameters: mobile phase: $75 \% \mathrm{MeOH} / 25 \% \mathrm{H}_{2} \mathrm{O}$ with $0.1 \%$ formic acid; detection: UV $232 \mathrm{~nm}$; injection volume: $50 \mu \mathrm{L}$; run-time: $20 \mathrm{~min}$.

\section{g. Differential scanning fluorimetry (DSF) with PPARY LBD}

Cloning of PPARY LBD 
A cDNA sequence optimized for codon usage in E.coli $\mathrm{K} 12$ and coding for an Nterminal His10-tag followed in frame by a TEV cleavage side and the PPARY LBD (aa $234-505$ ) was cloned into the backbone of pET29b for expression under the control of the $\mathrm{T7}$ promoter.

\section{Protein Expression:}

E.coli BL21 DE3 was transformed with the described expression plasmid and the plasmid pGro7 for co-expression of GroEL/ES (chaperone plasmid set; TaKaRa Bio, Inc.). Cultures in LB medium containing $35 \mu \mathrm{g} / \mathrm{ml}$ kanamycin and $34 \mu \mathrm{g} / \mathrm{ml}$ chloramphenicol were grown at $37^{\circ} \mathrm{C}$ and $180 \mathrm{rpm}$. When OD600 reached $0.6-0.7$ the temperature was lowered to $18^{\circ} \mathrm{C}$ and expression of GroEL/ES was induced by addition of $1 \mathrm{~g} / \mathrm{L}$ L-arabinose. 30 minutes later expression of PPARY LBD was induced by the addition of $0.5 \mathrm{mM} \mathrm{IPTG}$ and the cultures were supplemented per liter with $\sim 200 \mu$ l Antifoam Y-30 (Sigma-Aldrich). After $14-18 \mathrm{~h}$ the cells were harvested by centrifugation (20 $\left.\mathrm{min}, 6000 \times \mathrm{g}, 4^{\circ} \mathrm{C}\right)$.

\section{Purification:}

A cell pellet from $2 \mathrm{I}$ of culture was thawed and resuspended in a total volume of 50 $\mathrm{ml}$ of lysis buffer $(400 \mathrm{mM} \mathrm{NaCl}, 25 \mathrm{mM}$ Tris pH 7.8, $20 \mathrm{mM}$ B-Mercaptoethanol, 10\% w/v Glycerol) supplemented with $25 \mathrm{mM}$ imidazole, $2 \mathrm{mM} \mathrm{MgSO}$, 750 Kunitz DNAse I, 250 Kunitz RNAse A, a spattle tip of lysozyme and one tablet of Roche complete EDTA-free protease inhibitor cocktail. After incubation for 30 minutes on wet ice the slurry was diluted with three volumes of IMAC buffer A (400 mM NaCl, $25 \mathrm{mM} \mathrm{NaPi}$ $\mathrm{pH}$ 7.8, $20 \mathrm{mM}$ B-Mercaptoethanol, 10\% w/v Glycerol) supplemented with $25 \mathrm{mM}$ imidazole and cell lysis was enforced by passage through a homogenizer at a combined pressure of $1000 \mathrm{psi}$. The suspension was supplemented with $1 \mathrm{mM}$ ATP and incubated for another $30 \mathrm{~min}$ on wet ice. Cell debris was removed by centrifugation ( $20 \mathrm{~min}, 16500 \times \mathrm{g}, 4^{\circ} \mathrm{C}$ ) and the supernatant was loaded at a flowrate of $3 \mathrm{ml} / \mathrm{min}$ onto a prepacked $5 \mathrm{ml}$ HisTrap FF column (Ge Healthcare) preequilibrated in 95\% IMAC buffer A and 5\% IMAC buffer B (IMAC buffer A containing $500 \mathrm{mM}$ imidazole). To remove unbound proteins the column was washed with 15 column volumes of the same buffer at $5 \mathrm{ml} / \mathrm{min}$. PPARY LBD was eluted by a linear gradient of $20-60 \%$ IMAC buffer B and supplemented with His7-tagged TEV protease (molar ration of 1:25) for digestion of the His-tag during overnight dialysis against a volume of IMAC buffer A sufficient to reduce imidazole to $10-15 \mathrm{mM}$. The mixture was run gravity flow through a column packed with $10 \mathrm{ml} \mathrm{Ni}$ Sepharose 6 Fast Flow (Ge Healthcare) and the flow through was concentrated under 2 bar overpressure from nitrogen gas in an amicon stirring cell equipped with a 10.000 MWCO membrane. $5 \mathrm{ml}$ concentrate were separated on a HiLoad 16/600 Superdex $75 \mathrm{pg}$ gel filtration column (Ge Healthcare) equilibrated and run in assay buffer (150 $\mathrm{mM} \mathrm{NaCl}, 20 \mathrm{mM}$ Tris $\mathrm{pH} 8.0$ ) at $1 \mathrm{ml} / \mathrm{min}$. The protein used in thermal shift experiments was taken from the middle of the peak corresponding to monomeric PPARY LBD. 


\section{DSF assay:}

The assay was carried out in a 96-well plate. $5 \mu \mathrm{M}$ of protein $(20 \mathrm{mM}$ Tris, $150 \mathrm{mM}$ $\mathrm{NaCl}, \mathrm{pH} 8$ with $0.01 \%$ Triton-X 100) were mixed with $100 \mu \mathrm{M}$ (final concentration) of inhibitor. The final amount of DMSO was adjusted to $1 \%$ and the assay was performed at a total volume of $40 \mu \mathrm{L}$. A buffer reference (without protein and inhibitor) as well as a protein reference (without inhibitor) was measured. Sypro Orange $\AA(2.5 \mathrm{x})$ was added and the relative fluorescence intensity at dependence of the temperature (from $20^{\circ} \mathrm{C}$ to $90^{\circ} \mathrm{C}, 1^{\circ} \mathrm{C}$ steps every 0.24 min.) was recorded with the iCycler IQ Single-Color real time PCR. The first deviation was formed and a second order smoothing function with 6 neighbors was used (Graph Pad Prism 5.0).

\section{References}

(1) Christiansen, E.; Due-Hansen, M. E.; Urban, C.; Grundmann, M.; Schmidt, J.; Hansen, S. V. F.; Hudson, B. D.; Zaibi, M.; Markussen, S. B.; Hagesaether, E.; Milligan, G.; Cawthorne, M. a.; Kostenis, E.; Kassack, M. U.; Ulven, T. Discovery of a Potent and Selective Free Fatty Acid Receptor 1 Agonist with Low Lipophilicity and High Oral Bioavailability. Journal of Medicinal Chemistry 2013, 56, 982-992. 